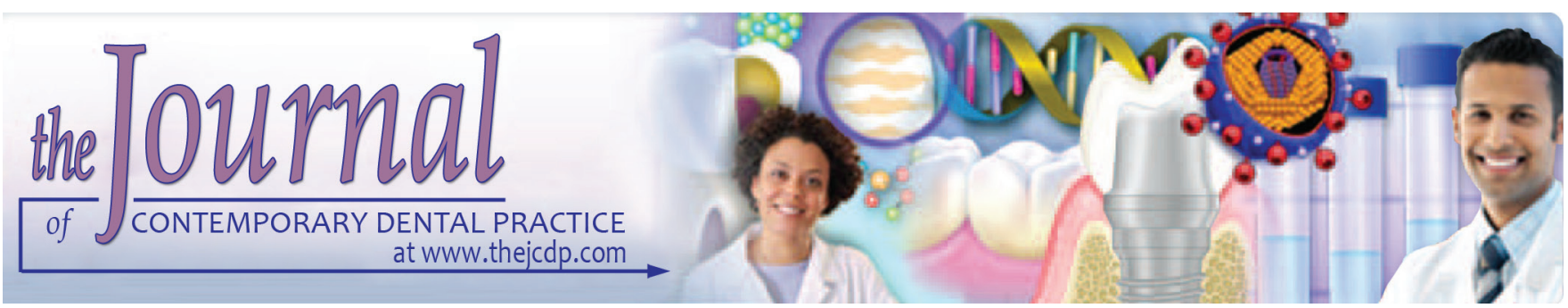

\title{
Effects of using Antifungal Gel on Retentive Bond Strength of Two Forms of Denture Adhesives: An in vitro Study
}

${ }^{1}$ Ghadeer I Basunbul, ${ }^{2}$ Abdulelah M BinMahfooz, ${ }^{3}$ Khaled K El-Din Amin, ${ }^{4}$ Mosa M Altassan

${ }^{5}$ Osama A Qutub, ${ }^{6}$ Sahar MN Bukhary

\begin{abstract}
Aim: The purpose of this in vitro study is to compare the bond strength to denture acrylics efficacy of miconazole gel against two denture adhesives with improved retentive properties (zincfree PoliGrip cream and Snug denture soft cushion).
\end{abstract}

Materials and methods: Eight heat-cured acrylic samples were prepared measuring $0.7 \mathrm{~cm} \times 1.4 \mathrm{~cm}$ flat tested surface. The two well-adapted tested surfaces were matched and fixed to Universal Testing Machine clamp. Vertical separating load was applied at a rate of $1 \mathrm{~mm} / \mathrm{min}$ to yield the maximum load before denture adhesive failure occurs. These measurements were used to express the retention bond strength when improved denture adhesive material was applied alone in comparison with miconazole nitrate gel. Results were analyzed using one-way analysis of variance (ANOVA) statistical analysis at $p$-value of $<0.05$.

Results: There was a statistically significant reduction in the mean tensile strength when the antifungal gel was opposed by the zinc-free PoliGrip cream. However, such a significant difference was not evident when the Snug denture cushion was opposed by the miconazole gel.

Conclusion: The addition of antifungal gel to denture adhesives reduces retentive bond strength of denture adhesives to denture acrylics. However, if an antifungal gel has to be used, then a denture adhesive cushion soft plastic liner may provide a better retentive option than denture adhesive cream.

Clinical significance: The incorporation of an antifungal agent into denture adhesives is required in many denture patients to

\footnotetext{
${ }^{1-5}$ Department of Oral and Maxillofacial Prosthodontics, Faculty of Dentistry, King Abdulaziz University, Jeddah, Kingdom of Saudi Arabia

${ }^{6}$ Department of Oral Biology, Faculty of Dentistry, King Abdulaziz University, Jeddah, Kingdom of Saudi Arabia

Corresponding Author: Ghadeer I Basunbul, Department of Oral and Maxillofacial Prosthodontics, Faculty of Dentistry, King Abdulaziz University, Jeddah, Kingdom of Saudi Arabia, e-mail: gbasunbul@gmail.com
}

suppress fugal growth and eliminate the undesirable health effects associated with such infections.

Keywords: Antifungal denture adhesives, Antifungal miconazole nitrate, Denture adhesive retention, Snug denture cushion, Zinc-free PoliGrip cream.

How to cite this article: Basunbul GI, BinMahfooz AM, El-Din Amin KK, Altassan MM, Qutub OA, Bukhary SMN. Effects of using Antifungal Gel on Retentive Bond Strength of Two Forms of Denture Adhesives: An in vitro Study. J Contemp Dent Pract 2018;19(8):943-948.

\section{Source of support: Nil}

Conflict of interest: None

\section{INTRODUCTION}

The quality of life (QoL) may be compromised as a result of complete edentulism and wearing complete dentures due to the dentures' poor stability and retention, especially, the mandibular dentures. ${ }^{1}$

Normally, alveolar bone resorption starts immediately and progresses rapidly within the first 3 to 12 months after teeth extraction. However, residual ridge resorption would continue at different rates throughout the patient's life. ${ }^{2}$ This resorption affects the denture-bearing structures negatively resulting in decreased retention and stability of constructed conventional dentures. Different methods have been developed to improve both retention and stability of old dentures including denture rebasing or relining, denture adhesives, and endosseous dental implants. ${ }^{3}$

Denture adhesives are used to adhere a denture to the underlying oral mucosa. ${ }^{1}$ Its prime objective is to improve denture retention, decrease soft tissue soreness and discomfort, mucosal infections, and reduce the need for frequent visits to the dental office for the management of postinsertion complaints and denture adjustments. ${ }^{4,5}$ 
It is a fact that the proper application of denture adhesives to the fitting surfaces of dentures will result in an increase in the interfacial surface tension between the denture base and the supporting soft tissue. This property will improve the adhesive, cohesive, and viscosity characteristics of the interfacial film formed between the denture base and the soft tissue, especially among those patients with reduced salivary flow. ${ }^{4}$ Moreover, denture adhesives eliminate the possibility of existence of voids in the interfacial space in the absence of absolute adaptation of the denture base to the bearing tissues. ${ }^{6,7}$ Due to the improved retention and stability, mucosal irritation and food accumulation underneath the denture base were reduced. ${ }^{8}$ In addition, this may improve chewing efficiency, biting force, functional load distribution over the denture-bearing tissues, as well as patient satisfaction. ${ }^{5}$ According to Nicolas et al, ${ }^{9}$ patients reported improvement in both QoL and oral health quality after denture adhesives were given to use 3 months in advance. Patients were actually able to use their dentures efficiently.

One of the main problems associated with the use of dentures and denture adhesives is denture stomatitis. This form of oral candidiasis occurs frequently in elderly patients, and in those who wear a complete maxillary denture, especially in individuals who leave their denture constantly in the mouth without regular cleaning. ${ }^{10}$ Many topical antifungal medications could be used to treat denture-related stomatitis, such as nystatin, amphotericin, miconazole, fluconazole, or itraconazole. Chlorhexidine antimicrobial mouthwash can also be prescribed to prevent or treat such condition. ${ }^{11}$ For this reason, the incorporation of an antifungal agent into denture adhesives is essential to deal with denture stomatitis and all the associated health hazards.

The objective of this in vitro study is to compare the bond strength to denture acrylics efficacy of an antifungal medicament miconazole gel in combination with two different forms of denture adhesives (Zinc-free PoliGrip cream and Snug denture soft cushion).

\section{MATERIALS AND METHODS}

\section{Acrylic Samples}

Eight $0.7 \times 1.4 \times 4.0 \mathrm{~cm}$ acrylic samples were cured using the conventional open flask heat curing technique. First, samples were prepared in molding wax. The tested surfaces of the wax samples were smoothened down by compressing the warm wax against wet glass slab. Then, the wax samples were flasked. As wax elimination was completed, polymer and monomer mixture was packed according to manufacturer's instructions and processed in a water tank at $70^{\circ} \mathrm{C}$ for 90 minutes and then at $100^{\circ} \mathrm{C}$ for 30 minutes. ${ }^{12}$
Acrylic resin samples were finished using 600 grit carbide papers. Two well-adapted and smooth $0.7 \mathrm{~cm} \times$ $.4 \mathrm{~cm}$ acrylic surfaces were used for the application of denture adhesives and the antifungal gel fitted in between. The two adapted tested surfaces were rechecked for the predetermined dimensions.

The acrylic samples were divided into four main groups I, II, III, and IV with two acrylic samples in each group. Two well-adapted tested surfaces were chosen and labeled for each group to preserve the position of the sample in each measurement.

\section{Preparation of Acrylic Tested Samples before Fixation on Universal Testing Machine Clamps}

- Group I: One sample was immersed in water, while $2 \mathrm{~mL}$ of commercial denture adhesive cream (zinc-free PoliGrip cream, Ultra-GlaxoSmithKline, Philadelphia, PA) was applied by plastic syringe and spread on the top of the dry acrylic surface of the other sample. ${ }^{13}$

- Group II: One sample was immersed in water, then $2 \mathrm{~mL}$ of antifungal gel (Miconazole-base 2\%, Jamjoom Pharmaceutical co., Saudi Arabia) was applied by plastic syringe on the wet tested surface. Commercial denture adhesive cream was applied and spread on the top of the dry acrylic surface of the other sample as in group I. ${ }^{14}$

- Group III: One sample was immersed in water. A piece of denture cushion soft plastic sheet (Snug, Mentholatum Co.Ltd, East Kilbride, Scotland G74 5PE,UK) was cut into a $1.4 \times 0.7 \mathrm{~cm}$ dimension and applied to the dry tested surface of the other sample following the manufacturer's instructions.

- Group IV: One sample was immersed in water, then $2 \mathrm{~mL}$ of antifungal gel (Miconazole-base $2 \%$, Jamjoom Pharmaceutical co., Saudi Arabia) was applied on the wet tested surface. A piece of denture cushion soft plastic sheet was applied to the dry tested surface of the other sample as in group III (Fig. 1).

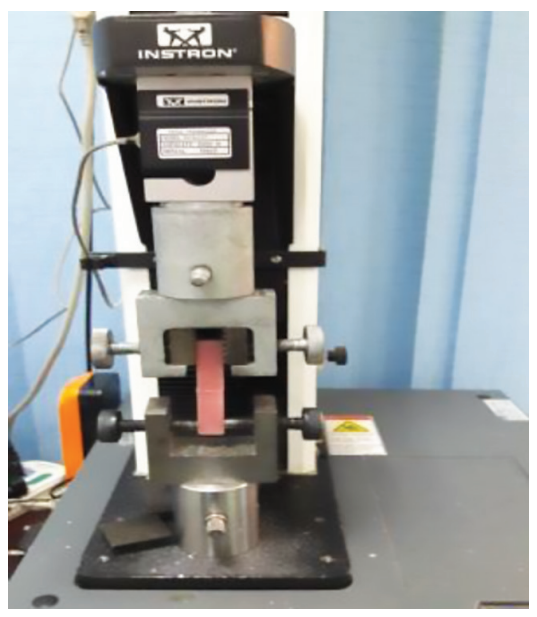

Fig. 1: Acrylic samples fixed to the Universal Testing Machine 
Effects of using Antifungal Gel on Retentive Bond Strength

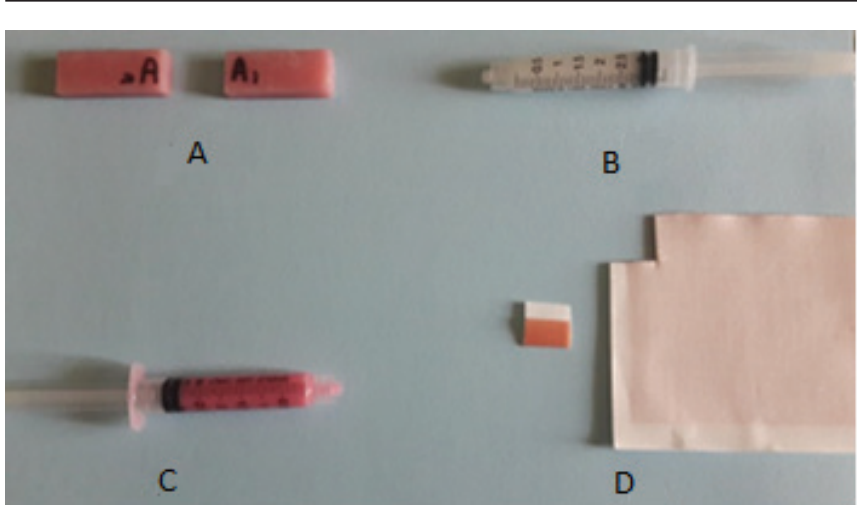

Figs 2A to D: (A) Labeled acrylic samples, (B) plastic syringe loaded with miconazole nitrate $2 \%,(C)$ plastic syringe loaded with zinc-free PoliGrip cream, and (D) cut piece of denture soft cushion $(1.4 \mathrm{~cm} \times 0.7 \mathrm{~cm})$

The two tested labeled surfaces for each group were assembled face to face and fixed to a testing machine using a specially designed grasping device that held the acrylic resin samples. The tensile bond strength was measured by Universal Testing Machine (Model 3345; Instron Industrial Products, Norwood, USA, Fig. 2) with a load cell of $5 \mathrm{kN}$. Data were recorded using computer software (Bluehill Lite; Instron Instruments, USA). The two acrylic tested surfaces were initially subjected to an average compression load of 12 to $15 \mathrm{~N}$ for 30 seconds to simulate a gentle occluding force for groups I and II and for 5 minutes for groups III and IV before applying the separating vertical loading. The device was subjected to a slowly increasingly vertical separating load at a rate of $1 \mathrm{~mm} / \mathrm{min}$ until total separation of upper and lower acrylic tested surfaces occurred accompanied by a decline in load-displacement curve as recorded by the software (Bluehill Lite software). The maximum load before failure was recorded in Newton force representing the adhesive retentive strength. To express bond strength in mega Pascal, the recorded load was divided by the interfacial area of the tested acrylic surfaces. ${ }^{14}$

Tensile bond strength measurement was repeated seven times for each group using the Universal Testing Machine (Fig. 2). Acrylic samples were cleaned before each measurement with neutral soap, washed with distilled water, and dried with paper towel. ${ }^{14}$

All collected data were statistically analyzed using one-way ANOVA using Statistical Package for the Social Sciences version 21 software (IBM Inc., Chicago, Illinois, USA). The significance level of the data was determined by the $\mathrm{p}$-value; $\mathrm{p}$-values $>0.05$ were considered nonsignificant and $\mathrm{p}$-values $<0.05$ were considered significant.

\section{RESULTS}

The measurements of maximum tensile bond strength of well-adapted two acrylic tested surfaces, just before
Table 1: Mean and SD of studied groups

\begin{tabular}{llll}
\hline Groups & Sample size $(n)$ & Mean & SD \\
\hline I & 7 & 22.34 & 1.994 \\
II & 7 & 11.27 & 1.205 \\
III & 7 & 18.98 & 1.437 \\
IV & 7 & 17.57 & 1.932 \\
\hline
\end{tabular}

Table 2: Comparison between means of different studied groups

\begin{tabular}{lcl}
\hline Comparison & Mean difference & Significance (p-value) \\
\hline Groups I vs II & 11.07148 & 0 \\
Groups III vs IV & 1.26308 & 0.171 \\
Groups I vs III & 3.35813 & 0.001 \\
Groups II vs IV & -6.45027 & 0 \\
\hline
\end{tabular}

sample separation, were done and statistically analyzed using one-way ANOVA. These measurements indicated the retention strength of two studied denture adhesive forces when either used alone or in the presence of the antifungal gel. The mean and standard deviation (SD) were reported in the different groups; $p$-values $\leq 0.05$ were considered significant (Table 1).

The statistically analyzed data also revealed a significant difference among the different study groups where $p$-values $<0.05$ were considered significant. The mean difference between groups I and II showed a significant reduction in tensile bond strength in the presence of the antifungal gel as compared with the denture adhesive cream used alone. The results also showed significantly higher tensile bond strength in group III, in which denture cushion Snug sheet was used, in comparison with group I where denture adhesive cream was used alone. Comparing groups III with IV indicated no significant changes in the tensile bond strength. Finally, the results revealed that the tensile bond strength of group IV exhibited a significant higher mean difference than group II (Table 2).

\section{DISCUSSION}

Despite dentists' advice and recommendation, the use of denture adhesives is widespread. Many denture users stated that they use denture adhesives without any advice from their dentists with the primary goal of improving their denture retention time and stability as well as to deal with the discomfort associated with loose dentures. ${ }^{15,16}$

Denture adhesives may be categorized into three main categories: adhesives, antimicrobial agents, and others. ${ }^{17}$ These agents have been marketed in different formulations, such as powders, pastes, or creams for soluble adhesives, and strips or cushions for insoluble adhesives. ${ }^{18}$ The increased viscosity of adhesive creams allows their lateral spread precluding air or saliva entrapment, which improves retention. Denture cushion may 
mold itself easily to the shape of the fitting surface of the denture offering a customized fit. It is mostly recommended for short-term use and has the advantage of not leaving a sticky mess in patients' mouth. Some, however, find making the cushion custom fit quite difficult and time-consuming, especially for older patients who lack perfect neuromuscular coordination. ${ }^{17}$ However, Salman and Ibrahim ${ }^{19}$ concluded that different types of denture adhesives were accepted by most patients whether vegetable gum or synthetic polymer, powder, or paste, as they all can improve the retention of complete dentures.

Candida albicans is an oral habitant isolated from 45 to $65 \%$ of healthy individuals. It has affinity for denture acrylics. ${ }^{20}$ According to research-based knowledge, Candida frequently colonizes in old denture wearer patients, especially those with poor oral hygiene, mechanical trauma sites from ill-fitting dentures, and/ or questionable suppressed immune response. ${ }^{10,21}$ This colonization may lead to the development of varying degrees of denture-related stomatitis in up to 11 to $67 \%$ of complete denture wearers. ${ }^{22}$

Some commercially available denture adhesives introduce microbial contamination while others have an inhibitory effect on C. albicans growth. ${ }^{23}$ Makihira et $\mathrm{al}^{12}$ investigated the growth of a single isolate of $C$. albicans and Candida tropicalis on six different denture adhesives by recording the $\mathrm{pH}$ changes in their growth media. Different denture adhesives presented variable $\mathrm{pH}$ changes in the growth media, indicating fungal growth. Only one product (Collect Soft A) significantly showed reduced $\mathrm{pH}$ below 5.0 after Candida growth on the materials and thus reduced $C$. tropicalis growth.

The American Dental Association system may be used to prevent and treat different forms of oral candidiasis through controlled release of antifungal medications from the polymer matrix. ${ }^{20}$ Garaicoa et $a{ }^{13}$ confirmed that antifungal agents keep their antifungal activities after they had been added to denture adhesive. This suggests the possibility of antifungal agents' inclusion in adhesive formulations and their use as topical treatments for individuals suffering from denture stomatitis. Scher et $\mathrm{al}^{24}$ evaluated the addition of amphotericin, an antifungal agent, into a denture adhesive formula and prescribed to patients suffering from Candida-related denture stomatitis. They did not reveal a statistically significant reduction in fungal levels, but the prevalence of denture stomatitis conditions was reduced.

Duqum et $\mathrm{al}^{3}$ reported concerns about the cytotoxicity of few denture adhesive formulations. They reported based on eight published papers documenting the unsafety potential of denture adhesives. Two of these eight studies reported a connection between zinc toxicity and denture adhesives use. Zinc is an antimicrobial agent used in many medicaments including denture adhesives and other cutaneous medications. The recommended daily allowances for zinc are $8 \mathrm{mg}$ for women and $11 \mathrm{mg}$ for men, with a tolerable upper limit of $12 \mathrm{mg}$ per day. Acute zinc overdose can cause headaches, cramps, diarrhea, and loss of appetite, nausea, and vomiting. Moreover, Nations et a ${ }^{25}$ reported progressive neurological symptoms associated with excessive and prolonged use of zinccontaining denture adhesives. Duqum et $\mathrm{al}^{3}$ recommended that long-term studies on the biologic effects of denture adhesives are warranted. Until then, establishing a regular recall program for complete denture patients is a necessity.

This study analyzes the effect of miconazole gel on retention strength using two forms of commercial denture adhesive. Cream form denture adhesive shows more resistance to dislodging forces when compared with the powder form which causes patient discomfort sensation. ${ }^{26}$ PoliGrip adhesive cream showed significant retention strength as concluded by Kamran et $\mathrm{al}^{5}$ and An et al. ${ }^{27}$ The higher retention bond between PoliGrip adhesive creams and denture acrylic was emphasized in our study as well. However, the addition of miconazole gel in our study to the PoliGrip adhesive cream reduced its retention strength significantly when compared with the addition of the same antifungal agent to Snug denture soft cushion..$^{28}$ Denture cushion is a temporary solution that provides an acceptable level of adhesiveness to denture and mucosa. It is adaptable soft plastic plate that has refit capability to loose dentures and a different consistency characters, which may interfere with the mixture of miconazole as what would occur with an adhesive cream. Equal amounts of denture adhesive cream and miconazole were used to eliminate the factor of amount in retention strength studies. ${ }^{1,14}$

Acrylic samples were made from heat-cured acrylic resin and were cured according to the widely used conventional open flask heat-curing technique. The acrylic sample tested surfaces were prepared flat smooth to facilitate adaptation. ${ }^{12}$ The tested acrylic samples were wet by water before tensile strength testing was performed to simulate the oral cavity hydration status which enhances the adhesive effectiveness. ${ }^{29,30} \mathrm{~A}$ compression load was applied to the contact tested surface before separating vertical loading of tensile strength in order to mimic the closing occluding load that patients were advised to do as the manufacturer's instructions stated. Miconazole nitrate is one of the first broad spectrum triazole antifungal agents used in the treatment of superficial mucosal candidiasis. The gel form is the most available formula miconazole nitrate. ${ }^{14}$

PoliGrip denture adhesive cream is composed of poly(methylvinylether/maleic acid) sodium-magnesiumzinc mixed partial salt, mineral oil, petrolatum, cellulose gum, silica, poly (methylvinylether/maleic acid), flavor, 
Red30 aluminum lake, and Red 7 calcium lake. ${ }^{27}$ The mechanism of adhesiveness was demonstrated by Salman and Ibrahim, ${ }^{19}$ as Karaya gum or carboxymethyl cellulose comes in contact with saliva, the hydrate material is formed, swells in the presence of saliva/water, and flows under pressure, and so eliminates voids between denture base and bearing tissue and increase the viscosity of saliva. The results showed a decrease in the retention strength with miconazole gel $v$ s the PoliGrip cream. This is because the miconazole gel, after compression loading, was enforced in denture adhesive cream. Miconazole nitrate has a very low aqueous solubility, leading to erratic and unpredictable bioavailability. ${ }^{14}$ Moreover, denture adhesive cream contains more hydrophobic compounds, such as hydrocarbon vehicles (mineral oil and petroleum), which may affect polymer hydration and gel formation and, thus, the adhesion behavior. Finally, the initiation of adhesive failure is mediated via the chemical interactions at the adhesive/polymethyl methacrylate interface, and continues through fibril formation until complete failure occurs. ${ }^{27}$ The location of denture adhesive failure, either at an interface (adhesive failure) or in the bulk of the adhesive (cohesive failure), was not detected in this study. This could be analyzed by further investigation using atomic force microscopy and assessment of material remnants in between the two tested acrylic surfaces. ${ }^{31,32}$

On the contrary, results of this study showed that denture adhesive cushion plates have higher retention strength when compared with denture adhesive PoliGrip cream as opposed by miconazole gel. This could be attributed to the physical and mechanical nature of the insoluble plastic plate structure that could resist inclusion of miconazole gel and/or the capability of plastic plates to squeeze miconazole gel out the adhesive/acrylic interface. ${ }^{28}$

\section{ACKNOWLEDGMENT}

Steve M Harakeh, Special Infectious Agents Unit, King Fahd Medical Research Center; King Abdulaziz University.

\section{CONCLUSION}

During treatment of oral candidiasis by antifungal gel (miconazole $2 \%$ ), denture adhesive cushion soft plastic liner (Snug cushion) could be used, if other indicating factors permit, instead of denture adhesive cream (nonzinc PoliGrip cream). However, newly developed denture adhesives including antifungal agent could be another treatment option.

\section{REFERENCES}

1. Mañes JF, Selva EJ, De-Barutell A, Bouazza K. Comparison of the retention strengths of three complete denture adhesives: an in vivo study. Med Oral Patol Oral Cir Bucal 2011 Jan;16(1):e132-e136.

2. Tallgren A. The continuing reduction of the residual alveolar ridges in complete denture wearers: a mixed-longitudinal study covering 25 years. J Prosthet Dent 1972 Feb;27(2):120-132.

3. Duqum I, Powers KA, Cooper L, Felton D. Denture adhesive use in complete dentures: clinical recommendations and review of the literature. Gen Dent 2012 Nov-Dec;60(6):467-477, quiz pp. 478-479.

4. Han JM, Hong G, Dilinuer M, Lin H, Zheng G, Wang XZ, Sasaki $K$. The adhesive strength and initial viscosity of denture adhesives. Acta Odontol Scand 2014 Nov;72(8):839-845.

5. Kamran MF, Chaudhary MA, Qamar K. Clinical comparison of retention strengths of two denture adhesives. Pak Oral Dent J 2016 Jul-Sep;36(3):507-511.

6. Hang F, Barber AH. Nano-mechanical properties of individual mineralized collagen fibrils from bone tissue. J R Soc Interface 2011 Apr;8(57):500-505.

7. Shekar S, Mittal S, Kalra N. Denture adhesives-a literature review. Dentistry 2016 Feb;6(3):364.

8. Kumar MS, Thombare RU. A comparative analysis of the effect of various denture adhesives available in market on the retentive ability of the maxillary denture: an in vivo study. J Indian Prosthodont Soc 2011 Jun;11(2):82-88.

9. Nicolas E, Veyrune Jl, Lassauzay C. A six-month assessment of oral health-related quality of life of complete denture wearers using denture adhesive: a pilot study. J Prosthodont 2010 Aug;19(6):443-448.

10. Mason KL, Erb Downward JR, Mason KD, Falkowski NR, Eaton KA, Kao JY, Young VB, Huffnagle GB. Candida albicans and bacterial microbiota interactions in the cecum during recolonization following broad-spectrum antibiotic therapy. Infect Immun 2012 Oct;80(10):3371-3380.

11. Gendreau L, Loewy ZG. Epidemiology and etiology of denture stomatitis. J Prosthodont 2011 Jun;20(4):251-260.

12. Makihira S, Nikawa H, Satonobu SV, Jin C, Hamada T. Growth of Candida species on commercial denture adhesives in vitro. Int J Prosthodont 2001 Jan-Feb;14(1):48-52.

13. Garaicoa JL, Fischer CL, Bates AM, Holloway J, Avila-Ortiz G, Guthmiller JM, Johnson GK, Stanford C, Brogden KA. Promise of combining antifungal agents in denture adhesives to fight Candida species infections. J Prosthodont 2016 Nov.

14. Cartagena AF, Esmerino LA, Polak-Junior R, Parreiras SO, Michél MD, Farago PV, Campanha NH. New denture adhesive containing miconazole nitrate polymeric microparticles: antifungal, adhesive force and toxicity properties. Dent Mater 2017 Feb;33(2):e53-e61.

15. Hasegawa S, Sekita T, Hayakawa I. Effect of denture adhesive on stability of complete dentures and the masticatory function. J Med Dent Sci 2003 Dec;50(4):239-247.

16. Adisman IK. The use of denture adhesive as an aid to denture treatment. J Prosthet Dent 1989 Dec;62(6):711-715.

17. Kumar PR, Shajahan PA, Mathew J, Koruthu A, Aravind P, Ahammed MF. Denture adhesives in prosthodontics: an overview. J Int Oral Health 2015;7(Suppl 1):93-95.

18. Pradies G, Sanz I, Evans O, Martinez F, Sanz M. Clinical study comparing the efficacy of two denture adhesives in complete denture patients. Int J Prosthodont 2009 Jul-Aug;22(4): 361-367.

19. Salman YM, Ibrahim IK. Effect of denture adhesives on the retention of maxillary complete denture. J Baghdad Coll Dent 2005;17(1):30-35. 
20. Park J-B, Prodduturi S, Morott J, Kulkarni VI, Jacob MR, Khan SI, Stodghill SP, Repka MA. Development of an antifungal denture adhesive film for oral candidiasis utilizing hot melt extrusion technology. Expert Opin Drug Deliv 2015 Jan;12(1):1-13.

21. Liguori G, Di Onofrio V, Lucariello A, Gallé F, Signoriello G, Colella G, D'Amora M, Rossano F. Oral candidiasis: a comparison between conventional methods and multiplex polymerase chain reaction for species identification. Oral Microbiol Immunol 2009 Feb;24(1):76-78.

22. Llabot JM, Palma SD, Manzo RH, Allemandi DA. Design of novel antifungal mucoadhesive films: part II. Formulation and in vitro biopharmaceutical evaluation. Int J Pharm 2007 May;336(2):263-268.

23. Sampaio-Maia B, Figueiral MH, Sousa-Rodrigues P, Fernandes $\mathrm{MH}$, Scully C. The effect of denture adhesives on Candida albicans growth in vitro. Gerodontology 2012 Jun;29(2):e348-e356.

24. Scher EA, Ritchie GM, Flowers DJ. Antimycotic denture adhesive in treatment of denture stomatitis. J Prosthet Dent 1978 Dec;40(6):622-627.

25. Nations SP, Boyer PJ, Love LA, Burritt MF, Butz JA, Wolfe GI, Hynan LS, Resich J, Trivedi JR. Denture cream an unusual source of excess zinc, leading to hypocupremia and neurologic disease. Neurology 2008 Aug;71(9):639-643.
26. Chowdhry P, Phukela SS, Patil R, Yadav H. A study to evaluate the retentive ability of different denture adhesive materials: an in vitro study. J Indian Prosthodont Soc 2010 Sep;10(3): 176-181.

27. An Y, Li D, Roohpour N, Gautrot JE, Barber AH. Failure mechanisms in denture adhesives. Dent Mater 2016 May;32(5):615-623.

28. Snug denture cushion specifications. Denture adhesive guide. Scotland G74 5PE, UK. East Kilbride: Mentholatum Co. Ltd; Available from: www.dentureadhesiveguide.com/ snug-denture-cushions/.

29. Panagiotouni E, Pissiotis A, Kapari D, Kaloyannides A. Retentive ability of various denture adhesive materials: an in vitro study. J Prosthet Dent 1995 Jun;73(6):578-585.

30. Guo X, Deng F, Li L, Prud'homme RK. Synthesis of biocompatible polymeric hydrogels with tunable adhesion to both hydrophobic and hydrophilic surfaces. Biomacromolecules 2008 Jun;9(6):1637-1642.

31. Dadarlat VM, Post CB. Adhesive-cohesive model for protein compressibility: an alternative perspective on stability. Proc Natl Acad Sci U S A 2003 Dec;100(25):14778-14783.

32. Marshall SJ, Bayne SC, Baier R, Tomsia AP, Marshall GW. A review of adhesion science. Dent Mater 2010 Feb;26(2): e11-e16. 